\title{
Status Pemanfaatan Energi Baru Terbarukan dan Opsi Nuklir Dalam Bauran Energi Nasional
}

\author{
Ruslan* \\ Pusat Kajian Sistem Energi Nuklir (PKSEN), Badan Tenaga Nuklir Nasional, Jl. Kuningan Barat, Mampang Prapatan, Jakarta- \\ Indonesia
}

\begin{tabular}{l} 
INFORMASI ARTIKEL \\
\hline Riwayat Artikel: \\
Diterima: \\
15 Desember 2020 \\
Diterima dalam bentuk revisi: \\
21 Mei 2021 \\
Disetujui: \\
14 Juni 2021
\end{tabular}

Kata kunci:

EBT

KEN

nuklir

gas rumah kaca

\begin{abstract}
ABSTRAK
STATUS PEMANFAATAN ENERGI BARU TERBARUKAN DAN OPSI NUKLIR DALAM BAURAN ENERGI NASIONAL. Peraturan Pemerintah Nomor 79 tahun 2014 tentang Kebijakan Energi Nasional (KEN) mentargetkan pemanfaatan Energi Baru Terbarukan (EBT) dalam bauran energi nasional paling sedikit $23 \%$ pada tahun 2025 dan paling sedikit $31 \%$ pada tahun 2050 . Pada tahun 2019 realisasi pemanfaatan EBT baru mencapai 9,15\% atau baru mencapai 39,8\% dibandingkan dengan target pada tahun 2025. Sementara itu di dalam KEN energi nuklir ditetapkan sebagai pilihan terakhir dalam pemenuhan kebutuhan energi nasional. Penelitian ini bertujuan untuk mengetahui status pengembangan EBT di Indonesia dikaitkan dengan pencapain target yang telah ditetapkan dalam KEN dan opsi pemanfaatan energi nuklir dalam pemenuhan kebutuhan energi nasional. Metode yang digunakan dalam penelitian adalah studi referensi atas data sekunder dari bahan pustaka/publikasi/dokumentasi, untuk selanjutnya dilakukan komparasi terkait studi yang dilakukan tersebut dan dilakukan analisa kuantitatif dan kualitatif atas beberapa indikator atau parameter yang ditetapkan. Hasil penelitian menunjukkan realisasi penyediaan energi primer, pemanfaatan EBT dan penyediaan pembangkit tenaga listrik sampai dengan tahun 2019 masih lebih rendah daripada yang ditargetkan. Untuk mencapai target yang ditetapkan dalam KEN pada tahun 2025 dan 2050 perlu ada perbaikan arah kebijakan dan konsistensi dalam pelaksanaannya. Energi nuklir diperkirakan bisa dimanfaatkan setelah tahun 2030 untuk memenuhi kebutuhan energi nasional dan mengurangi emisi gas rumah kaca.
\end{abstract}

\begin{abstract}
STATUS OF NEW RENEWABLE ENERGY UTILIZATION AND NUCLEAR OPTIONS IN THE NATIONAL ENERGY MIX. Government Regulation Number 79 of 2014 concerning National Energy Policy (NEP) targets the use of New and Renewable Energy (NRE) in the national energy mix of at least $23 \%$ in 2025 and at least $31 \%$ in 2050. In 2019 the realization of the use of new and renewable energy only reached $9.15 \%$ or it has only reached $39.8 \%$ compared to the target in 2025. Meanwhile in NEP, nuclear energy is set as the last option in meeting national energy needs. This study is intended to determine the status of renewable energy development in Indonesia in relation to achieving the targets set in the NEP and options for using nuclear energy in meeting national energy needs. The method used in this research is a reference study of secondary data from library materials / publications / documentation, for subsequent comparisons between the various sources of literature and quantitative and qualitative analysis of several determined indicators or parameters. The results showed that the realization of primary energy supply, utilization of NRE and provision of power plants by 2019 was still lower than targeted. To achieve the targets set in the NEP in 2025 and 2050 there needs to be an improvement in policy direction and consistency in its implementation. Nuclear energy is estimated to be utilized after 2030 to meet national energy needs and reduce greenhouse gas emissions.
\end{abstract}

Keywords: NRE, NEP, nuclear, greenhouse gas

(C) 2016 Jurnal Pengembangan Energi Nuklir. All rights reserved

\section{PENDAHULUAN}

Pasokan energi primer di Indonesia masih didominasi oleh sumber energi fosil seperti minyak bumi, batubara, dan gas, sedangkan pasokan dari Energi Baru Terbarukan (EBT) masih rendah. Mengingat cadangan energi fosil Indonesia yang terbatas maka dipandang perlu untuk segera

*Penulis korespondensi.

E-mail: ruslan23@batan.go.id mengoptimalkan pemanfaatan sumber EBT [1] [2].

Sementara itu Indonesia memiliki berbagai jenis energi baru terbarukan yang belum dimanfaatkan secara optimal. Peraturan Pemerintah Nomor 79 tahun 2014 tentang Kebijakan Energi Nasional (KEN) mengamanatkan pengurangan secara bertahap penggunaan energi fosil dan mendorong pemanfaatan EBT. Pada tahun 2025 peran EBT 
dalam bauran energi nasional ditargetkan paling sedikit 23\% dan pada tahun 2050 paling sedikit $31 \%$ [3]. Pada tahun 2019 realisasi pemanfaatan EBT baru mencapai 9,15\%, atau baru mencapai 39,8\% dibandingkan dengan target pada tahun 2025 [4].

Masih minimnya porsi pemanfaatan EBT dalam bauran energi nasional disebabkan oleh beberapa kendala yang dihadapi diantaranya adalah kesenjangan geografis antara lokasi sumber energi dengan lokasi kebutuhan energi serta biaya investasi teknologi energi berbasis EBT yang masih mahal. Selain itu ada juga faktor lainnya yaitu tidak adanya konsistensi arah kebijakan dalam perencanaan energi dan ketenagalistrikan antara berbagai peraturan perundangan yang berlaku [5] [6].

Berdasarkan beberapa studi diketahui bahwa ketergantungan terhadap energi fosil secara terus menerus akan menimbulkan dampak negatif terhadap lingkungan dalam bentuk pencemaran lingkungan, perubahan iklim, dan pemanasan global [7] [8]. Perlunya peningkatan pemanfaatan EBT dalam pemenuhan kebutuhan energi nasional salah satunya adalah untuk mengurangi dampak gas rumah kaca (GRK) yang disebabkan oleh pembangkit bahan bakar fosil. Apalagi berdasarkan UU Nomor 16 Tahun 2016 tentang Pengesahan Paris Agreement to the United Nations Framework Convention on Climate Change (Persetujuan Paris atas Konvensi Kerangka Kerja Perserikatan Bangsa-Bangsa mengenai Perubahan Iklim), pemerintah Indonesia berkomitmen menurunkan GRK sebesar 29\% (tanpa bantuan) dan 41\% (dengan bantuan internasional) dari total seluruh sektor pada tahun 2030 [4] [9].

Penelitian ini bertujuan untuk mengetahui status pengembangan EBT di
Indonesia sampai dengan tahun 2019 dalam kaitannya dengan pemenuhan target yang telah ditetapkan dengan mengacu pada beberapa dokumen perencanan energi dan ketenagalistrikan serta mengetahui capaian realisasi komitmen Pemerintah untuk menurunkan emisi gas rumah kaca di Indonesia.

Selain status pengembangan EBT yang sudah banyak dilakukan studi sebelumnya juga akan dibahas bagaimana kedudukan energi nuklir dalam bauran energi nasional, apakah tetap menjadi pilihan terakhir sebagaimana disebutkan dalam KEN atau sudah mulai harus dipertimbangkan pemanfaatannya. Juga bagaimana peran energi nuklir dalam mendukung penurunan emisi gas rumah kaca.

\section{POKOK BAHASAN}

\subsection{Kerangka hukum pengembangan EBT}

Peraturan Presiden (PP) Nomor 79 Tahun 2014 tentang Kebijakan Energi Nasional (KEN) menetapkan politik bauran energi nasional sampai tahun 2025 dan tahun 2050. Peran EBT dalam bauran energi primer pada tahun 2025 paling sedikit 23\% dan pada tahun 2050 paling sedikit 31\%. Sementara porsi energi fosil, khususnya minyak bumi dan batubara, secara bertahap akan dikurangi. Sasara-sasaran yang diamanatkan dalam KEN dijabarkan secara lintas sektoral dalam Rencana Umum Energi Nasional (RUEN) dapat dilihat pada Tabel 1 [10]. RUEN disusun oleh Pemerintah dan ditetapkan oleh Dewan Energi Nasional (DEN).

Tabel 1. Sasaran yang diamanatkan dalam KEN Tahun 2015-2050 [10].

\begin{tabular}{|c|c|c|c|c|c|c|}
\hline No. & Sasaran KEN & Satuan & 2015 & 2020 & 2025 & 2050 \\
\hline 1 & Penyediaan energi primer & MTOE & & & $>400$ & $>1.000$ \\
\hline \multirow[t]{5}{*}{2} & Target bauran energi: & & & & & \\
\hline & a. EBT & $\%$ & & & $>23$ & $>31$ \\
\hline & b. Minyak bumi & $\%$ & & & $<25$ & $<20$ \\
\hline & c. Batubara & $\%$ & & & $>30$ & $<25$ \\
\hline & d. Gas bumi & $\%$ & & & $>22$ & $>24$ \\
\hline 3 & Penyediaan pembangkit tenaga listrik & GW & & & $>115$ & $>430$ \\
\hline 4 & Rasio elektrifikasi & $\%$ & 85 & 100 & & \\
\hline 5 & Pemanfaatan energi primer per kapita & TOE & & & 1,4 & 3,2 \\
\hline 6 & Pemanfaatan listrik per kapita & KWh & & & 2.500 & 7.000 \\
\hline 7 & Elastisitas energi & & & & $<1$ & \\
\hline 8 & Penurunan intensitas energi final & $\%$ & & & $r$ tahun & \\
\hline 9 & Rasio penggunaan gas rumah tangga & $\%$ & 85 & & & \\
\hline
\end{tabular}


Selain melalui KEN dan RUEN, target bauran EBT juga dijabarkan dalam Rencana Umum Ketenagalistrikan (RUKN) 2019-2038. RUKN disusun berdasarkan KEN dan merujuk pada RUEN, serta ditetapkan oleh Pemerintah setelah berkonsultasi dengan DPR dengan melibatkan Pemerintah Daerah. Jika RUEN memuat rencana pengelolaan energi tingkat nasional, maka RUKN memuat kebijakan ketenagalistrikan nasional dan rencana pengembangan sistem penyediaan sistem tenaga listrik. Dalam RUKN 2019-2038 pada tahun 2025 ditargetkan bauran EBT minimum $23 \%$, gas sekitar 22\%, batubara sekitar 55\%, dan BBM sekitar 0,4\%. Sementara pada tahun 2038, ditargetkan bauran EBT minimum 28\%, gas sekitar 25\%, batubara sekitar $47 \%$, dan BBM sekitar 0,1\% [11].

Selanjutnya di dalam dokumen Rencana Pembangunan Jangka Menengah Nasional (RPJMN) 2020-2024 ditetapkan target bauran EBT pada tahun 2020 sebesar 13,4\% dan pada tahun 2024 sebesar 20\%. Target tersebut mengharuskan Indonesia meningkatkan 4,25\% bauran EBT untuk mencapai target di tahun 2020 (pada tahun 2019 bauran EBT sebesar 9,15\%) dan peningkatan sebesar 3\% pada tahun 2025 untuk memenuhi target KEN jika berpatokan pada target RPJMN 2020-2024

Indonesia memiliki berbagai potensi EBT yang dapat dimanfaatkan untuk memenuhi target bauran energi primer. Sebagian besar EBT dimanfaatkan untuk pembangkit listrik dan sisanya untuk sektor transportasi, industri, komersial, dan sektor lainnya sebagai bahan baku campuran biodiesel dan bioetanol. Total potensi EBT ekuivalen 417,8 GW, yang baru dimanfaatkan sekitar 10,4 GW (2,5\%) [12].

\subsection{Berbagai permasalahan dalam pencapaian target EBT}

\subsubsection{Dominasi energi fosil}

Untuk mencapai sasaran bauran EBT dalam KEN, maka kapasitas penyediaan pembangkit listrik EBT tahun 2025 harus sekitar 45,2 GW dan pada tahun 2050 sekitar 167,7 GW. Kapasitas terpasang pembangkit listrik nasional sampai akhir tahun 2019 adalah sebesar 69,6 GW. Pembangkit Listrik Tenaga Uap (PLTU) masih mendominasi kapasitas nasional yaitu sebesar 34,7 GW (49,9\%), disusul Pembangkit Listrik Tenaga Gas (PLTG) sebesar 19,9 GW (28,6\%). Sementara kapasitas pembangkit listrik EBT sekitar 10,4 GW $(14,8 \%)$ dan Pembangkit Listrik Tenaga Disel (PLTD) sebesar 4,6 GW (6,7\%) [13].

Kapasitas terpasang pembangkit tenaga listrik nasional mengalami penambahan rata-rata sekitar 4,9\% per tahun selama 5 tahun terakhir. Apabila dilihat per tahun, kapasitas pembangkit tumbuh sekitar 3,5\% pada tahun 2014, 4,6\% pada tahun 2015, 7,4\% pada tahun 2016, 4,3\% pada tahun 2017, dan 4,4\% pada tahun 2018. Penambahan kapasitas pembangkit secara total sekilas relatif besar namun sebarannya kurang proporsional, dimana daerah di Jawa Bali memiliki kecukupan pasokan sementara sebagian daerah di luar Jawa Bali mengalami keterbatasan [10].

Dalam Rencana Umum Pembangkit Tenaga Listrik (RUPTL) 2019-2028 tambahan kapasitas pembangkit selama 10 tahun mendatang untuk seluruh Indonesia adalah 56,6 GW atau pertambahan kapasitas rata-rata mencapai 5,6 GW per tahun. PLTU Batubara akan mendominasi pembangkit yang akan dibangun yaitu mencapai 27,1 GW (48,0\%), PLTGU dengan kapasitas 9,1 GW (16,2\%), PLTG/MG sebesar 3,3 GW (5,8\%). Sisa sebesar 16,9 GW berasal dari EBT dimana yang terbesar adalah PLTA/PLTM sebesar 9,7 GW $(17,2 \%)$ dari kapasitas total, disusul PLTP sebesar 4,6 GW $(8,2 \%)$ [14].

Dengan melihat kondisi kapasitas pembangkit tenaga listrik saat ini sebesar 69,6 GW dan penambahan kapasitas pembangkit tenaga listrik nasional rata-rata sekitar 4,9\% per tahun, apakah target pada tahun 2025 yaitu minimal 115 GW dan pada tahun 2050 minimal 400 GW bisa tercapai?

\subsubsection{Komitmen internasional}

Selain target peningkatan pemanfaatan EBT dalam bauran energi nasional, Pemerintah Indonesia juga telah berkomitmen untuk ikut berkontribusi dalam menurunkan emisi gas rumah kaca (GRK). Berdasarkan dokumen Nationally Determine Contribution (NDC) yang disampaikan kepada United Nations Framework Convention on Climate Change (UNFCCC) target emisi sektor energi pada tahun 2030 sebesar 1.355 juta ton $\mathrm{CO}_{2}$ untuk skenario CM1 (tanpa bantuan internasional) dengan target penurunan 
emisi 29\% dari kondisi skenario dasar tahun 2010 sebesar 453 juta $\mathrm{CO}_{2}$ eq. Sedangkan target emisi untuk skenario CM2 (dengan bantuan internasional) sebesar 1.271 juta ton $\mathrm{CO}_{2}$ eq dengan target penurunan emisi $41 \%$ dari kondisi skenario dasar. Target penurunan emisi $\mathrm{CO}_{2}$ per sektor dapat dilihat pada Tabel 2 [12].

\subsubsection{Belum dimanfaatkannya energi nuklir}

Energi nuklir merupakan bagian dari EBT yang belum dimanfaatkan sampai dengan saat ini. Walaupun peran energi nuklir untuk pembangkit listrik sebenarnya sudah diatur dalam berbagai peraturan perundangan. Dimulai dengan Undang-undang Nomor 7 Tahun 2007 tentang Rencana Pembangunan Jangka Panjang Nasional (RPJPN) tahun 2005 - 2025 dimana pada Rencana Pembangunan Jangka Menengah (RPJM) ke-3 tahun 2015-2019 disebutkan "......terpenuhinya pasokan listrik yang handal dan efisien sesuai kebutuhan sehingga elektrifikasi rumah tangga dan elektrifikasi pedesaan dapat tercapai, serta mulai dimanfaatkannya tenaga nuklir untuk pembangkit listrik dengan mempertimbangkan faktor keselamatan secara ketat;… [15].

$$
\text { Selanjutnya dalam Peraturan }
$$

Pemerintah Nomor 79 Tahun 2014 tentang Kebijakan Energi Nasional (KEN) dan Peraturan Presiden Nomor 22 Tahun 2017 tentang Rencana Umum Energi Nasional (RUEN), disebutkan bahwa energi nuklir yang dimanfaatkan dengan mempertimbangkan keamanan pasokan energi nasional dalam skala besar, mengurangi emisi karbon dan tetap mendahulukan potensi Energi Baru dan Energi Terbarukan sesuai nilai keekonomiannya, serta mempertimbangkannya sebagai pilihan terakhir dengan memperhatikan faktor keselamatan secara ketat [3][10]

Walaupun energi nuklir dianggap sebagai pilihan terakhir tapi dalam bagian Penjelasan Peraturan Pemerintah tersebut disebutkan bahwa dalam hal telah dilakukan kajian yang mendalam mengenai adanya teknologi pengembangan energi nuklir untuk tujuan damai, pemenuhan kebutuhan energi yang semakin meningkat, penyediaan energi nasional dalam skala besar, mengurangi emisi karbon, serta adanya kepentingan nasional yang mendesak maka pada dasarnya energi nuklir dapat dimanfaatkan [3].

Namun demikian dalam Penjelasan atas Peraturan Pemerintah Nomor 14 Tahun 2015 tentang Rencana Induk Pembangunan Industri Nasional (RIPIN) Tahun 2015-2035, disebutkan bahwa kelangkaan energi telah mulai dirasakan dan untuk menjamin keberlangsungan pembangunan industri diperlukan kebijakan penghematan dan diversifikasi energi serta perhatian yang lebih besar terhadap pengembangan sumber energi terbarukan dan energi nuklir yang murah dan aman [16].

Berdasarkan pentahapan pembangunan industri dan penetapan industri prioritas dalam RIPIN, disebutkan bahwa industri Pembangkit Listrik Tenaga Nuklir (PLTN) akan dikembangkan pada tahun 2020-2024 dan 2025-2035. Teknologi rekayasa nuklir (fisi) akan dikembangkan pada tahun 2015-2019 dan 2020-2024, sedangkan teknologi rekayasa nuklir (fisi \& fusi) akan dikembangkan pada tahun 2025-2035.

Tabel 2 Target Penurunan Emisi $\mathrm{CO}_{2}$ per Sektor(Sumber: Outlook Energi Indonesia 2019[12]).

\begin{tabular}{|c|c|c|c|c|c|c|c|c|c|c|c|}
\hline \multirow{3}{*}{ No } & \multirow{3}{*}{ Sektor } & \multirow{3}{*}{$\begin{array}{c}\text { Tingkat } \\
\text { Emisi } \\
\text { GRK } \\
2010 \\
\text { (Mton } \\
\mathrm{CO}_{2} \\
\text { eq.) } \\
\end{array}$} & \multirow{2}{*}{\multicolumn{3}{|c|}{$\begin{array}{l}\text { Tingkat Emisi GRK } 2030 \\
\left(\text { Mton } \mathrm{CO}_{2} \text { eq }\right)\end{array}$}} & \multicolumn{4}{|c|}{ Penurunan Emisi GRK } & \multirow{3}{*}{$\begin{array}{c}\text { Rerata } \\
\text { Pertumbuhan } \\
\text { Tahunan } \\
\text { BaU }\end{array}$} & \multirow{3}{*}{$\begin{array}{c}\text { Rerata } \\
\text { Pertumbuhan } \\
\text { Tahun } \\
\text { 2000-2012* }\end{array}$} \\
\hline & & & & & & \multicolumn{2}{|c|}{ (Mton $\mathrm{CO}_{2}$ eq) } & \multicolumn{2}{|c|}{$\%$ Total BaU } & & \\
\hline & & & $\mathrm{BaU}$ & CM1 & CM2 & CM1 & CM2 & CM1 & CM2 & & \\
\hline 1 & Energi* & 453.2 & 1,669 & 1.355 & 1.271 & 314 & 398 & $11 \%$ & $14 \%$ & $6.70 \%$ & $4.50 \%$ \\
\hline 2 & Limbah & 88 & 296 & 285 & 270 & 11 & 26 & $0.38 \%$ & $1 \%$ & $6.30 \%$ & $4.00 \%$ \\
\hline 3 & IPPU & 36 & 69.6 & 66.85 & 66.35 & 2.75 & 3.25 & $0.10 \%$ & $0.11 \%$ & $3.40 \%$ & $0.10 \%$ \\
\hline 4 & Pertanian & 110.5 & 119.66 & 110.39 & 115.86 & 9 & 4 & $0.32 \%$ & $0.13 \%$ & $0.40 \%$ & $1.30 \%$ \\
\hline \multirow[t]{2}{*}{5} & Kehutanan** & 647 & 714 & 217 & 64 & 497 & 650 & $17.20 \%$ & $23 \%$ & $0.50 \%$ & $2.70 \%$ \\
\hline & Total & 1,334 & 2.869 & 2.034 & 1.787 & 834 & & $29 \%$ & $38 \%$ & $3.90 \%$ & $3.20 \%$ \\
\hline
\end{tabular}

* Termasuk fugitive ** Termasuk kebakaran gambut

Notes CM1 = Counter Measure 1 (kondisi tanpa persyaratan mitigasi-unconditional)

$\mathrm{CM} 2=$ Counter Measure 2 (kondisi dengan persyaratan mitigasi-unconditional) 
Pernyataan yang sama dengan KEN dan RUEN tentang pemanfaatan energi nuklir juga ditemui dalam dokumen RUKN 20192038 yaitu mempertimbangkannya sebagai pilihan terakhir. Namun pernyataan yang agak berbeda terdapat dalam RUPTL 20192028 yang menyebutkan bahwa PLTN masih merupakan opsi yang dimunculkan untuk mencapai target bauran energi dari EBT sekitar $23 \%$ yang implementasinya memerlukan program pembangunan PLTN yang diputuskan oleh Pemerintah. Untuk itu perlu dilakukan langkah nyata persiapan proyek pembangunan PLTN mengingat sumber energi fosil yang semakin langka dan mempertimbangkan masa pembangunan PLTN yang sangat lama [14].

Desakan untuk peningkatan
pemanfaatan EBT di Indonesia semakin kuat dengan adanya Rancangan Undang-undang (RUU) EBT yang pada saat ini masih dalam tahap pembahasan di DPR-RI. UU EBT tersebut diperlukan sebagai payung hukum yang kuat untuk mengakselerasi pengembangan EBT di Indonesia. Opsi tentang energi nuklir juga menjadi bahan diskusi yang hangat. Sebagian berpendapat bahwa pemanfaatan energi nuklir sebaiknya tidak dimasukkan dalam materi RUU EBT karena sudah ada UU Nomor 10 Tahun 1997 tentang Ketenaganukliran. Tapi sebagian yang lainnya berpendapat agar opsi nuklir tetap dimasukkan dalam materi RUU EBT, karena UU No.10 Tahun 1997 lebih banyak mengatur tentang kegiatan penelitian dan pengembangan, bukan untuk kepentingan komersial

Melihat realisasi pemanfaatan EBT pada saat ini dan target yang dicapai pada tahun 2025 dan 2050 apakah pemanfaatan energi nuklir akan dipertimbangkan setelah pemanfaatan sumber EBT dimaksimalkan atau memang sudah saatnya energi nuklir dipertimbangkan untuk mulai direalisasikan guna mendukung penyediaan energi yang handal dan ramah lingkungan.

\section{METODE}

Metode yang digunakan dalam penelitian ini berupa studi referensi atas data sekunder yang diperoleh dari berbagai bahan pustaka, publikasi, dan dokumentasi. Berdasarkan data yang diperoleh selanjutnya dilakukan komparasi antara berbagai sumber pustaka tersebut dan dilakukan analisa kuantitatif dan kualitatif atas beberapa indikator atau parameter (antara lain target penyediaan energi primer, pemanfaatan EBT, dan penyediaan pembangkit tenaga listrik) yang telah ditetapkan oleh peraturan perundangan dan ketentuan lainnya yang berlaku.

\section{HASIL DAN PEMBAHASAN}

Pencapaian sasaran penyediaan energi primer dalam 5 tahun terakhir adalah sebagai berikut: 182,42 MTOE (2015), 173,55 MTOE (2016), 188,11 MTOE (2017), 205,25 MTOE (2018), 219,08 MTOE (2019). Selain tahun 2016 tampak ada peningkatan penyediaan energi primer dari tahun ke tahun. Tetapi peningkatannya tidak terlalu signifikan. Jika realisasi tahun 2019 dibandingkan dengan target tahun 2025 sebesar 400 MTOE maka capaiannya baru sekitar 54,77\%. Realisasi penyediaan dan pemanfaatan energi nasional yang masih di bawah target tersebut disebabkan karena pertumbuhan ekonomi saat ini tidak tumbuh seperti yang diproyeksiakan sebesar $7 \%$ sampai dengan $8 \%$, di mana pertumbuhan ekonomi rata-rata hanya mencapai 5\%. Sangat berat untuk mencapai target penyediaan energi primer sesuai amanat KEN pada tahun 2025 jika masih terpaku pada skema Business as Usual (BaU) seperti yang berjalan selama ini [4].

Dari target penyediaan energi primer sebanyak 400 MTOE pada tahun 2025, sebesar 23\% atau 92,2 MTOE diharapkan dapat dipasok EBT. Pada tahun 2019 penyediaan energi primer sebanyak 219,08 MTOE, dimana EBT menyumbang 20,4 MTOE atau baru sekitar 9,15\%, masih di bawah target RUEN sebesar 12,2\% [4].

Untuk mencapai target pemanfaatan EBT yang ditetapkan dalam KEN, RUEN, RUKN dan RPJMN dirasakan sangat berat mengingat perkembangan porsi EBT dalam bauran energi primer nasional tidak terlalu signifikan.

Pada tahun 2019 realisasi EBT baru mencapai $9,15 \%$, yang terbesar batubara 
$37,15 \%$, selanjutnya minyak bumi $33,58 \%$, dan gas bumi 20,12\%. Jika dihitung berdasarkan realisasi EBT pada tahun 2019 sebesar 9,15\% maka untuk mencapai target 23\% EBT pada tahun 2025 berarti diperlukan tambahan $13,85 \%$ atau perlu kenaikan ratarata $2,31 \%$ per tahun.

Demikian juga jika melihat kapasitas terpasang pembangkit listrik nasional dalam 5 tahun terakhir yaitu 54,7 GW (2015), 58,4 GW (2016), 62,2 GW (2017), 64,9 GW (2018) dan 69,1 GW (2019). Artinya peningkatan kapsitas terpasang tiap tahunnya antara 2,7 GW - 4,2 GW. Sementara target pada tahun 2025 sebesar 115 GW, berarti perlu tambahan kapasitas pembangkit listrik sebesar 45,4 GW atau 7,56 GW per tahun. Sedangkan pada RUPTL 2019-2028 tambahan kapasitas pembangkit selama 10 tahun mendatang untuk seluruh Indonesia direncanakan sebesar 56,6 GW atau pertambahan kapasitas rata-rata mencapai 5,6 GW per tahun. Jika target RUPTL tersebut terealisasi maka kapasitas terpasang pembangkit listrik pada tahun 2025 adalah sebesar 102,7 GW masih lebih rendah dari target KEN sebesar 115 GW.

Perkembangan pembangkit listrik yang memanfaatkan EBT dalam 5 tahun terakhir adalah sebesar 500 MW per tahun. Kapasitas pembangkit listrik EBT pada tahun 2014 sebesar $10.081 \mathrm{MW}$, selanjutnya 10.541 MW (2015), 11.031 MW (2016), 11.425 MW (2017), 11.828 MW (2018), dan $10.300 \mathrm{MW} *$ (2019). Realisasi pembangkit listrik EBT pada tahun 2019 masih di bawah target RUEN sebesar 13,9 GW. Untuk mencapai target PLT EBT 23\% seperti yang ditetapkan RUEN pada tahun 2025 yaitu sebesar 45,2 GW MW akan sangat sulit dicapai jika penambahan PLT EBT hanya sebesar 500 MW per tahun sebagaimana yang terjadi dalam 5 tahun terakhir.

Belum tercapainya target penyediaan energi primer, masih rendahnya realisasi EBT dalam bauran energi nasional dan belum tercapainya target kapasitas terpasang pembangkit listrik disebabkan oleh banyak faktor. Salah satu diantarnya adalah tidak adanya konsistensi arah kebijakan dalam perencanaan energi dan ketenagalistrikan antara berbagai peraturan perundangan yang berlaku.
Sebagaimana diketahui ada 4 (empat) dokumen perencanaan yang digunakan dalam pengembangan energi dan ketenagalistrikan di Indonesia, yaitu : KEN, RUEN, RUKN, dan RUPTL. KEN merupakan dokumen perencanaan yang tertinggi yang mengatur arah kebijakan pengelolaan energi nasional. KEN selanjutnya dijabarkan lebih rinci dalam RUEN. Untuk penyusunan rencana penyediaan tenaga listrik maka disusun RUKN dan RUPTL dengan mempertimbangkan dokumen induknya maupun potensi yang ada di masing-masing daerah. Pada kenyataannya antara keempat dokumen tersebut dalam penyusunan dan implementasinya tidak sejalan satu dengan lainnya.

Sebagai contoh misalnya di dalam dokumen KEN disebutkan bahwa target penyediaan pembangkit listrik pada tahun 2025 adalah sebesar 115 GW. Sementara RUEN menargetkan 135 GW dan RUKN menargetkan 122 GW. Dari total target kapasitas pembangkit listrik tersebut, terdapat perbedaan dalam menentukan porsi 23\% EBT dalam dokumen RUEN dan RUKN. Porsi pembangkit listrik EBT dalam RUEN dihitung berdasarkan 23\% dari penyediaan energi primer pada tahun 2025 sebesar 400 MTOE sehingga porsi EBT adalah sebesar 92,2 MTOE dimana 69,2 MTOE digunakan sebagai pembangkit listrik 45,2 GW dan 23,0 MTOE digunakan sebagai bahan bakar. Sementara dalam RUKN porsi pembangkit listrik EBT dihitung berdasarkan 23\% dari target kapasitas pembangkit listrik terpasang pada tahun 2025 sebesar 122 GW dimana porsi pembangkit listrik EBT sebesar 28,06 GW. Sedangkan dalam RUPTL target kapasitas pembangkit listrik EBT pada tahun 2025 adalah sebesar 27,69 GW. Perbedaan target kapasitas pembangkit listrik EBT dalam RUEN sebesar 45,2 GW, dalam RUKN sebesar 28,06 GW dan dalam RUPTL sebesar 27,69 GW menunjukkan bahwa antara dokumen perencanaan satu dengan yang lainnya belum sejalan.

Contoh lainnya dalam dokumen RUEN disebutkan bahwa potensi sumber daya terbesar yang bisa dikembangkan di daerah Jawa dan Bali adalah PLT Panas Bumi. RUKN menetapkan potensi sumber daya setempat yang bisa dikembangkan di provinsi Jawa 
Barat adalah PLT Panas Bumi karena cadangannya yang sangat besar dan PLT Surya di provinsi Yogyakarta dengan cadangan lebih besar dari 11.000 MW. Akan tetapi dalam dokumen RUPTL disebutkan bahwa tumpuan pembangkit listrik di daerah Jawa dan Bali hingga 2025 adalah PLTU Batubara dengan penambahan jumlah kapasitas 12.386 MW hingga 2025. Adapun untuk panas bumi menjadi tumpuan kedua dengan penambahan kapasitas sebesar 2.500 MW. Hal ini juga terjadi di beberapa daerah lainnya. Tampaknya RUPTL belum didesain untuk menggunakan potensi energi setempat sebagai tumpuan pembangkit listrik di daerah tersebut.

Selain itu RUPTL juga belum didesain untuk memenuhi target total kapasitas pembangkit listrik sebesar $115 \mathrm{GW}$ pada tahun 2025 dan 430 GW pada tahun 2025. Sampai dengan tahun 2019 kapasitas pembangkit listrik terpasang baru sekitar 69,6 GW. Apabila keseluruhan jumlah rencana penambahan pembangkit listrik sampai dengan tahun 2025 yang ada dalam RUPTL yaitu sebesar 37,3 GW dijumlahkan dengan kapasitas pembangkit yang terpasang maka totalnya baru sekitar 106,9 GW, artinya masih ada kekurangan sekitar 8,1 GW [4].

Tabel 3. Perbandingan perencanaan pembangunan pembangkit listrik berbasis EBT antara RUEN dan RUPTL hingga 2025 [6].

\begin{tabular}{lcc}
\hline $\begin{array}{c}\text { Jenis } \\
\text { Pembangkit }\end{array}$ & $\begin{array}{c}\text { Rencana } \\
\text { pembangunan } \\
\text { dalam RUEN }\end{array}$ & $\begin{array}{c}\text { Rencana } \\
\text { pembangunan } \\
\text { dalam RUPTL }\end{array}$ \\
\hline Panas Bumi & $7.241,5 \mathrm{MW}$ & $6.184,7 \mathrm{MW}$ \\
Air & $13.986,7 \mathrm{MW}$ & $10.847,9 \mathrm{MW}$ \\
Minihidro dan & $1.572,1 \mathrm{MW}$ & $986,5 \mathrm{MW}$ \\
Mikrohidro & & \\
Bioenergi & $2.006 \mathrm{MW}$ & $187,5 \mathrm{MW}$ \\
Surya & $540,5 \mathrm{MW}$ & $149,81 \mathrm{MW}$ \\
Angin & $913,9 \mathrm{M}$ & $1.030,75 \mathrm{MW}$ \\
EBT lainnya & $372 \mathrm{MW}$ & $320,5 \mathrm{MW}$ \\
\hline \multicolumn{1}{c}{ Total } & $26.632,7 \mathrm{MW}$ & $19.697,66 \mathrm{MW}$ \\
\hline
\end{tabular}

Demikian juga dengan target untuk memenuhi rencana pengembangan EBT sebanyak 23\% atau sekitar $26 \mathrm{GW}$ pada tahun 2025, perencanaan dalam RUPTL belum didesain untuk mencapai target tersebut. Tabel 3 memperlihatkan perbandingan perencanaan pembangunan pembangkit listrik berbasis EBT antara RUEN dan RUPTL hingga 2025 [6].
Berdasarkan data tersebut tergambar bahwa perencanaan dalam RUPTL belum didesain untuk mencapai target $23 \%$ bauran EBT. Jika seluruh kapasitas pembangkit yang sudah ada per provinsi ditambahkan dengan rencana pembangunan pembangkit listrik hingga 2025, maka kapasitas maksimum dari pengembangan listrik berbasis EBT tersebut hanya sekitar $17 \%$.

Disadari bahwa pengembangan EBT bukan hal yang murah dan mudah untuk diterapkan di Indonesia, karena saat ini teknologi pengembangan EBT masih dikuasai pasar asing dan Indonesia masih ada di posisi sebagai importir teknologi EBT. Sehingga perlu biaya dan investasi yang cukup besar untuk beralih ke EBT sebagai sumber energi bersih masa depan. Hal tersebut yang menyebabkan kurang maksimalnya porsi pemanfaatan EBT untuk elektrifikasi karena terkendala dengan harga jual listrik EBT yang masih sulit bersaing dengan energi fosil. Selain itu ada permasalahan tumpang tindih dalam pemanfaatan hutan dalam pengembangan PLTP dan PLTA. Sementara pembangkit listrik EBT skala kecil umumnya berada di lokasi yang terpencil dan jauh dari infrastruktur pendukung jaringan listrik baik transmisi ataupun distribusi, sehingga untuk menyalurkan produksi tenaga listrik dari pembangkit melalui jaringan listrik membutuhkan investasi besar yang akan dibebankan kepada pengembang.

Jika melihat kondisi terkini dari perkembangan EBT di Indonesia, seluruh target EBT khususnya pada tahun 2025 hampir dipastikan tidak akan tercapai. Demi mendorong pemanfaatan EBT yang lebih masif, perlu ada perbaikan kebijakan, implementasi, kelembagaan, dan platform yang mewadahi informasi terkait perkembangan EBT. Diperlukan juga roadmap dan kepastian kebijakan untuk transisi energi fosil menuju EBT. Bila Indonesia masih terpaku pada skema business as usual (BAU) yang berjalan selama ini, maka Indonesia tidak akan siap menghadapi krisis energi karena terlalu bergantung pada bahan bakar fosil yang akan habis.

Salah satu upaya untuk mengakselerasi pemanfaatan EBT di Indonesia adalah dengan membuat Undang- 
undang khusus tentang Energi Baru Terbarukan. Pada saat ini Rancangan Undang-undang (RUU) EBT masih dalam tahap pembahasan di DPR-RI. RUU EBT diharapkan dapat mengisi kekosongan peran energi terbarukan yang belum secara jelas diuraikan dalam UU Nomor 30 Tahun 2007 tentang Energi. RUU EBT dapat menjadi payung hukum nasional yang kuat, sebab selama ini pengaturan mengenai energi terbarukan ada di tingkat aturan yang lebih rendah sehingga rentan terhadap perubahan dan preferensi menteri sektoral. RUU EBT tersebut juga diharapkan dapat menjadi rujukan yang lebih detail terkait pengelolaan EBT meliputi penguasaan sumber daya, penyediaan dan pemanfaatan, pengusahaan, hak dan kewajiban, kemudahan dan insentif, harga energi, penelitian dan pengembangan, hingga pembinaan dan pengawasan.

Perlunya peningkatan pemanfaatan EBT dalam pemenuhan kebutuhan energi nasional salah satunya adalah untuk mengurangi dampak gas rumah kaca (GRK) yang disebabkan oleh pembangkit bahan bakar fosil. Apalagi berdasarkan UU Nomor 16 Tahun 2016 tentang Pengesahan Paris Agreement to the United Nations Framework Convention on Climate Change (Persetujuan Paris atas Konvensi Kerangka Kerja Perserikatan Bangsa-Bangsa mengenai Perubahan Iklim), pemerintah Indonesia berkomitmen menurunkan GRK sebesar 29\% (tanpa bantuan) dan 41\% (dengan bantuan internasional) dari total seluruh sektor pada tahun 2030.

Pada tahun 2017 kontribusi penurunan emisi GRK secara nasional mencapai 709 juta ton $\mathrm{CO}_{2}$ atau 24,7\% dari target penurunan emisi sebesar 834 juta ton $\mathrm{CO}_{2}$ atau 29\% pada tahun 2030. Pada Tabel 4 dapat dilihat kontribusi pencapaian target Nationally Determine Contribution (NDC) pada tahun 2010-2017 [9].
Terlihat bahwa tingkat emisi GRK mengalami fluktuasi, bahkan pada tahun 2015 tingkat emisi jauh lebih tinggi dari BAU NDC. Pada tahun 2017 emisi aktual berada pada level 709 juta ton $\mathrm{CO}_{2}$ di bawah tingkat emisi baseline pada tahun 2017. Akan tetapi penurunan emisi pada tahun 2017 sebesar 24,7\% apabila dibandingkan dengan skenario CM1 dan CM2 maka masih diperlukan usaha lebih besar dari seluruh sektor untuk memenuhi target yang ditetapkan dalam NDC.

Menurut laporan World Resources Institute (WRI) tahun 2018, Indonesia menduduki peringkat keenam sebagai negara penghasil emisi $\mathrm{CO}_{2}$ tertinggi di dunia di bawah China, Amerika Serikat, Uni Eropa, India, dan Rusia. Total emisi karbon yang dihasilkan Indonesia mencapai 1.053 juta ton $\mathrm{CO}_{2}$.

Sektor energi merupakan salah satu sektor penyumbang emisi GRK terbesar di Indonesia. Apalagi kebutuhan energi sampai saat ini banyak dipasok oleh bahan bakar fosil. Ada peningkatan emisi $\mathrm{CO}_{2}$ sebesar 18\% sepanjang 2012-2017 yang disebabkan karena meningkatnya emisi dari pembangkit listrik, sektor industri dan sektor transportasi. Untuk sektor energi, sebagaimana telah ditetapkan dalam dokumen NDC Indonesia pemerintah menargetkan penurunan GRK sebesar $11 \%$ pada tahun 2030.

Di sektor energi, pemerintah telah mencanangkan target penurunan emisi GRK sebesar 314 juta ton $\mathrm{CO}_{2}$ pada tahun 2030. Sementara realiasi penurunan GRK di sektor energi dalam 6 tahun terakhir adalah 23,38 juta ton $\mathrm{CO}_{2}$ (2014), 29,64 juta ton $\mathrm{CO}_{2}$ (2015), 31,60 juta ton $\mathrm{CO}_{2}$ (2016), 33,90 juta ton $\mathrm{CO}_{2}$ (2017), 43,8 juta ton $\mathrm{CO}_{2}$ (2018), dan 54,80 juta ton $\mathrm{CO}_{2}$ (2019). Jika melihat capain penurunan GRK tersebut perlu upaya keras untuk mencapai target tahun 2030.

Tabel 4. Kontribusi Pencapaian Target NDC pada Tahun 2010-2017[9].

\begin{tabular}{cccccccccc}
\hline & $\begin{array}{c}\text { Target } \\
2030\end{array}$ & 2010 & 2011 & 2012 & 2013 & 2014 & 2015 & 2016 & 2017 \\
\hline $\begin{array}{c}\text { Tingkat Emisi Aktual } \\
\quad\left(\text { Mton } \mathrm{CO}_{2}\right)\end{array}$ & & 1116 & 1354 & 1478 & 1340 & 1767 & 2372 & 1457 & 1151 \\
$\begin{array}{c}\text { BAU NDC } \\
\left(\text { Mton } \mathrm{CO}_{2}\right)\end{array}$ & 2869 & 1334 & 1521 & 1570 & 1610 & 1670 & 1703 & 1768 & 1860 \\
$\begin{array}{c}\text { Penurunan Emisi } \\
\left(\text { Mton } \mathrm{CO}_{2}\right)\end{array}$ & 834 & 218 & 167 & 92 & 261 & -97 & -669 & 311 & 709 \\
\hline $\begin{array}{c}\text { Kontribusi Pencapai } \\
\text { Target NDC (\%) }\end{array}$ & 29 & 7.6 & 5.8 & 3.2 & 9.1 & -3.4 & -23.3 & 10.8 & 24.7 \\
\hline
\end{tabular}


Pemerintah telah menyusun estimasi kebutuhan investasi sebesar Rp 3.500 trilyun untuk mencapai target penurunan GRK sebesar 314 juta ton $\mathrm{CO}_{2}$ pada tahun 2030. Pembangkit listrik EBT ditargetkan dapat berkontribusi menurunkan emisi GRK sebesar 156,6 juta ton $\mathrm{CO}_{2}$ (atau 49,8\% dari total aksi mitigasi sektor energi) dengan kebutuhan investasi sebesar Rp 1.690 trilyun [17].

Untuk mencapai realisasi target yang telah ditetapkan dalam KEN dan penurunan GRK seharusnya semua potensi energi dimanfaatkan termasuk energi nuklir sebagai salah satu bagian dari EBT. Dalam KEN disebutkan ada beberapa syarat yang harus dipenuhi agar energi nuklir dapat dimanfaatkan yaitu antara lain mempertimbangkan keamanan pasokan energi nasional/pemenuhan kebutuhan energi yang meningkat, keselamatan/dampak radiasi terhadap lingkungan, mengurangi emisi karbon, dan nilai keekonomiannya kompetitif.

Dalam RUEN memang tidak disebutkan opsi nuklir untuk memenuhi kebutuhan energi pada tahun 2025-2050. EBT masih mengandalkan PLT panas bumi, PLT air, PLT minihidro \& mikrohidro, PLT bioenergi, PLT surya, PLT angin, dan PLT EBT lainnya sebagai sumber energi. Yang dimaksud PLT EBT lainnya antara lain PLTD dengan campuran bioenergi, PLT arus laut, PLT gelombang laut, PLT energi panas laut. Pengembangan EBT lainnya diproyeksikan sebesar 3,1 GW (2025), 3,7 GW (2030), 4,9 GW (2040) dan 6,1 GW (2050). Jika PLT EBT lainnya yang disebutkan dalam RUEN tersebut tidak dapat memenuhi kebutuhan energi pada tahun 2030-2050, seharusnya energi nuklir diberi peran untuk memenuhinya. Mengapa pada tahun 2030 bukan pada tahun 2025? Karena pembangunan suatu PLTN membutuhkan waktu selama 8-10 tahun maka PLTN diperkirakan baru dapat beroperasi setelah tahun 2030. Hal tersebut sejalan dengan kajian yang dilakukan oleh Badan Pengkajian Penerapan Teknologi (BPPT) bahwa PLTN diperkirakan akan masuk dalam sistem ketenagalistrikan Jawa-Bali pada tahun 2030 sebesar $2 \mathrm{GW}$ dan bertambah menjadi $8 \mathrm{GW}$ pada tahun 2050 [5].
Teknologi keselamatan PLTN telah berkembang sedemikian pesat, khususnya pasca kecelakaan PLTN Fukushima. Pada saat ini tengah dikembangkan PLTN Generasi III+ dengan desain passive system yaitu suatu sistem keselamatan yang mengandalkan pada perilaku alamiah (tidak memerlukan tindakan operator atau catu daya dalam pengoperasiannya) yang dapat meningkatkan derajat keselamatan PLTN. Dengan derajat keselamatan PLTN yang meningkat diharapkan dapat menjamin keselamatan masyarakat dan lingkungan dari potensi dampak beroperasinya PLTN. PLTN Generasi III+ menjadi suatu pilihan untuk pembangunan PLTN yang dilakukan dari sekarang hingga tahun 2030.

Salah satu teknologi PLTN yang dapat dipertimbangkan di Indonesia sebagai negara kepulauan adalah PLTN SMR (Small Modular Reactor). Kelebihan PLTN SMR adalah dayanya lebih kecil, investasi lebih kecil, produk pabrik, beberapa modular unit dalam satu area, bisa hybrid dengan EBT lain (termasuk inovasi dalam hybrid seperti untuk desalinasi, load-following, hybrid dengan off-shore wind). Namun perlu dikaji lebih lanjut terkait keekonomiannya karena PLTN SMR belum tersedia secara komersial. PLTN SMR sangat cocok dimanfaatkan di kepulauan Indonesia yang kebutuhan listriknya masih relatif kecil.

Pemanfaatan energi nuklir terbukti dapat mengurangi emisi GRK karena PLTN tidak melepaskan emisi GRK ketika beroperasi. Emisi GRK hanya dilepaskan dalam proses tidak langsung, yaitu pada saat proses konstruksi (berasal dari produksi semen, baja, pembuatan komponen), siklus bahan bakar, dan dekomisioning. Emisi spesifik energi nuklir sangat rendah, yaitu hanya 12 gram $\mathrm{CO}_{2}$ ekivalen per $\mathrm{kWh}$. Sebagai perbandingan, batubara tipe pulverised coal memiliki emisi spesifik 820 gram $\mathrm{CO}_{2}$ ekivalen per $\mathrm{kWh}$ dan gas alam sebesar 490 gram $\mathrm{CO}_{2}$ ekivalen per $\mathrm{kWh}$.

Negara-negara Eropa yang tergabung dalam Organization for Economic Cooperation and Development (OECD) berhasil mencegah pelepasan 23 Gigaton $\mathrm{CO}_{2}$ ekivalen dengan penggunaan energi nuklir. Sementara di Amerika Serikat pelepasan 20 Gigaton $\mathrm{CO}_{2}$ ekivalen berhasil dihindari 
dengan menggunakan energi nuklir. Sedangkan di Jepang dapat dicegah 6,2 Gigaton $\mathrm{CO}_{2}$ ekivalen dan di Rusia sebesar 6,1 Gigaton $\mathrm{CO}_{2}$ ekivalen. Sebagai catatan, 64 Gigaton $\mathrm{CO}_{2}$ ekivalen setara dengan emisi pembakaran batubara kumulatif di Amerika Serikat selama 35 tahun, atau di Cina selama 17 tahun [18].

Dari aspek ekonomi, biaya pembangkitan listrik nuklir ditentukan oleh tiga komponen utama yaitu biaya modal, biaya bahan bakar, dan biaya operasional dan pemeliharaan. Komponen biaya modal mencapai $\frac{3}{4}$ biaya total sehingga biaya pembangunan PLTN lebih mahal daripada biaya pembangunan PLT lainnya tetapi relatif murah biaya operasionalnya. Di banyak tempat, energi nuklir bersaing dengan bahan bakar fosil sebagai pembangkit listrik.

Dengan biaya modal yang tinggi, biaya pembangkitan listrik PLTN banyak dipengaruhi oleh faktor tingkat diskonto. Untuk tingkat diskonto 5\%, biaya pembangkitan listrik PLTN lebih murah dibanding dengan batubara dan gas di beberapa negara. Sedangkan untuk diskonto $10 \%$, nuklir lebih mahal dari batubara dan gas, kecuali di Korea nuklir masih lebih murah yaitu $4,2-4,8$ sen $\$ / \mathrm{kWh}$ sementara PLT batubara sebesar $7,1-7,4$ sen $\$ / \mathrm{kWh}$.

Berdasarkan hasil studi kelayakan pembangunan PLTN di Babel tahun 2013, biaya pembangkitan listrik PLTN besar berkisar 6-8 sen $\$ / \mathrm{kWh}$. Dengan biaya pembangkitan sebesar itu, PLTN baru akan layak jika harga jual listriknya 10 sen $\$ / \mathrm{kWh}$. Harga jual listrik sebesar itu memang di atas BPP (Biaya Pokok Penyediaan) listrik nasional yang sebesar 7 sen $\$ / k W h$, namun angka tersebut masih di bawah tarif listrik rata-rata di Indonesia yaitu sebesar 11 sen $\$ / k W h[19]$.

Energy Innovation Reform Project (EIRP) mengeluarkan laporan hasil studi nilai keekonomian jenis teknologi reaktor maju. Laporan itu mengungkapkan bahwa estimasi BPP listrik dari berbagai teknologi reaktor maju berkisar antara 30-90 sen $\$$ /MWh atau 3-9 sen $\$ / \mathrm{kWh}$.

Pada akhirnya pengambilan keputusan untuk membangun PLTN tidak semata-mata didasarkan pada pertimbangan keekonomian dan profitability, namun juga pertimbangan lain seperti aspek politik, target penggunaan EBT sesuai KEN, penerimaan sosial, budaya, perubahan iklim dan perlindungan lingkungan. Dengan adanya berbagai aspek yang multi dimensional tersebut, program pembangunan PLTN hanya dapat diputuskan oleh Pemerintah.

\section{KESIMPULAN}

Realisasi penyediaan energi primer, pemanfaatan EBT dan penyediaan pembangkit tenaga listrik sampai dengan tahun 2019 masih lebih rendah daripada yang ditargetkan. Untuk mencapai target yang ditetapkan dalam KEN pada tahun 2025 dan 2050 perlu ada perbaikan kebijakan, implementasi, kelembagaan, dan platform yang mewadahi informasi terkait perkembangan EBT. Arah kebijakan dalam perencanaan energi dan ketenagalistrikan harus sinergis dan harus dilakukan secara konsisten antara berbagai peraturan perundangan yang berlaku.

Kontribusi penurunan emisi GRK secara nasional pada tahun 2017 sebesar 24,7\%. Apabila dibandingkan dengan skenario CM1 dan CM2 masih diperlukan usaha lebih besar dari seluruh sektor untuk memenuhi target yang ditetapkan oleh NDC pada tahun 2030. Di sektor energi, EBT ditargetkan dapat berkontribusi sebesar 49,8\% dari total aksi mitigasi sektor energi.

Untuk memenuhi kebutuhan energi yang meningkat dan mengurangi emisi GRK, energi nuklir sebagai bagian dari EBT mulai dapat dimanfaatkan setelah tahun 2030. Akan tetapi pembangunan PLTN tidak hanya berdasarkan pada aspek keekonomian dan aspek keselamatan saja tetapi juga berbagai aspek multi dimensi lainnya yang keputusan pembangunannya hanya bisa ditetapkan oleh Pemerintah.

\section{UCAPAN TERIMA KASIH}

Ucapan terima kasih kami sampaikan kepada kepada semua pihak, khususnya di lingkungan Pusat Kajian Sistem Energi Nuklir, yang telah membantu dalam penyelesaian makalah kami 


\section{DAFTAR ACUAN}

[1] Partahi H. Lumbangaol. Energi Terbarukan untuk Pembangunan Berkelanjutan di Indonesia, Jurnal Fakultas Teknik Volume II Nomor 2 Tahun 2017, Universitas HKBP Nommensen, Medan, 2017.

[2] Lubis, Abubakar. Energi Terbarukan dalam Pembangunan Berkelanjutan, Jurnal Teknologi Lingkungan Vol. 8 No. 2 Tahun 2007 Halaman 155162, Badan Pengkajian dan Penerapan Teknologi, Jakarta, 2007.

[3] Kementerian Sekretariat Negara RI, Peraturan Pemerintah Nomor 79 Tahun 2014, Oktober 2014, Kebijakan Energi Nasional, Jakarta.

[4] Sekretariat Jenderal Dewan Energi Nasional, Agustus 2020, Bauran Energi Nasional 2020, Jakarta.

[5] Pusat Pengkajian Industri Proses dan Energi, Badan Pengkajian dan Penerapan Teknologi, , Outlook Energy Indonesia 2019, Jakarta November 2019.

[6] Grita Anindarini Widyaningsih, Membedah Kebijakan Perencanaan Ketenagalistrikan di Indonesia, Jurnal Hukum Lingkungan Indonesia, Vol. 5 No. 1 Tahun 2018 Halaman 131-132, Jakarta, 2018

[7] Nur Tri Harjanto, Dampak Lingkungan Pusat Listrik Tenaga Fosil dan Prospek PLTN sebagai Sumber Energi Listrik Nasional, Jurnal BATAN Vol. 1 No. 1 Tahun I Halaman 39-50, Pusat Pengelolaan Instalasi Nuklir, Jakarta, 2008.

[8] Sulistyono Sulistyono. Pemanasan Global (Global Warming) dan Hubungannya dengan Penggunaan Bahan Bakar Fosil, Majalah Swara Patra Vol. 2 No. 2 Tahun 2012 Halaman 47-56, Pusat Pengembangan Sumber Daya Manusia Minyak dan Gas Bumi, Blora, 2012.

[9] Direktorat Jenderal Pengendalian Perubahan Iklim, Kementerian Lingkungan Hidup dan Kehutanan, Maret 2019, Laporan Inventarisasi Gas Rumah Kaca dan Monitoring, Pelaporan Verifikasi Tahun 2018, Direktorat Inventarisasi Gas Rumah Kaca dan MPV, Jakarta, 2018.

[10] Sekretariat Kabinet RI, Peraturan Presiden Republik Indonesia Nomor 22 Tahun 2017, Maret
2017, Rencana Umum Energi Nasional, Jakarta, 2017.

[11] Kementerian Energi dan Sumber Daya Mineral, Keputusan Menteri Energi dan Sumber Daya Mineral Republik Indonesia Nomor 143K/20/MEM/2019, Agustus 2019, Rencana Umum Ketenagalistrikan Nasional 2019 - 2038, Jakarta/

[12] Sekretariat Jenderal Dewan Energi Nasional, September 2019, Outlook Energi Indonesia 2019, Jakarta/

[13] Ditjen Ketenagalistrikan Kementerian ESDM, Februari 2020, https://www.esdm.go.id/id/beritaunit/direktorat-jenderal-

ketenagalistrikan/kapasitas-pembangkit-listrikmeningkat-15-gw-dalam-lima-tahun diakses pada 4 Oktober 2020/

[14] Kementerian Energi dan Sumber Daya Mineral, Keputusan Menteri Energi dan Sumber Daya Mineral Republik Indonesia Nomor 39K/20/MEM/2019, Pengesahan Rencana Usaha Penyediaan Tenaga Listrik PT. Perusahaan Listrik Negara (Persero) Tahun 2019 sampai dengan Tahun 2028, Jakarta, Februari 2019.

[15] Sekretariat Negara RI, Undang-undang Nomor 7 Tahun 2007, Februari 2007, Rencana Pembangunan Jangka Panjang Nasional (RPJPN) tahun 2005 - 2025, Jakarta

[16] Kementerian Sekretariat Negara RI, Peraturan Pemerintah Nomor 14 Tahun 2015, Maret 2015, Rencana Induk Pembangunan Industri Nasional (RIPIN) Tahun 2015-2035, Jakarta

[17] Iman Rahman Cahyadi. September 2020, Emisi Gas Rumah Kaca Ditargetkan Menurun 314 Juta Ton co2 Hingga 2030, Berita Satu, https://www.beritasatu.com/iman-rahmancahyadi/nasional/680233/ emisi-gas-rumahkaca-ditargetkan-menurun-314-juta-ton- ${ }^{-\mathrm{CO}_{2}-}$ hingga-2030 diakses 23 Oktober 2020

[18] R. Andika Putra Dwijayanto, Mengukur Dampak Iklim dari Pemanfaatan Energi Nuklir, Warung Sains Teknologi, https://warstek.com/nukliriklim diakses pada 25 Oktober 2020.

[19] Pusat Kajian Sistem Energi Nuklir, Badan Tenaga Nuklir Nasional, Agustus 2019, Kajian Teknologi dan Ekonomi Pembangkit Listrik Tenaga Nuklir, Jakarta. 